\title{
Evaluation of the Cooking Cultures and Practices in Rural Uganda
}

\author{
Hussein Kisiki Nsamba ${ }^{*}$, Robert Ssali ${ }^{2}$, Sarah N. Ssali ${ }^{3}$, Fahad Matovu${ }^{1}$, \\ John Wasswa ${ }^{2}$, Hussein Kivumbi Balimunsi ${ }^{4}$
}

\begin{abstract}
${ }^{1}$ Section of Industrial Chemistry, Department of Chemistry, College of Natural Science, Makerere University, Kampala, Uganda ${ }^{2}$ Department of Chemistry, College of Natural Science, Makerere University, Kampala, Uganda

${ }^{3}$ School of Women and Gender Studies, College of Humanities and Social Sciences, Makerere University, Kampala, Uganda ${ }^{4}$ Department of Agricultural and Biosystems Engineering, College of Agricultural Science, Makerere University, Kampala, Uganda Email: `hnsamba@cns.mak.ac.ug
\end{abstract}

How to cite this paper: Nsamba, H.K., Ssali, R., Ssali, S.N., Matovu, F., Wasswa, J. and Balimunsi, H.K. (2021) Evaluation of the Cooking Cultures and Practices in Rural Uganda. Journal of Sustainable Bioenergy Systems, 11, 33-44.

https://doi.org/10.4236/jsbs.2021.111003

Received: December 21, 2020

Accepted: March 19, 2021

Published: March 22, 2021

Copyright (c) 2021 by author(s) and Scientific Research Publishing Inc. This work is licensed under the Creative Commons Attribution International License (CC BY 4.0).

http://creativecommons.org/licenses/by/4.0/

\begin{abstract}
Many communities across the globe still practice poor cooking cultures as part of their well-being to prepare food and other heating activities. Such bad cooking practices are not environmentally friendly, are wasteful and have adverse health effects. This work presents the results of the survey that was conducted to establish the existing cooking practices commonly used in Uganda, identify the commonly used fuel during cooking, identify perceptions on improved cooking stoves (ICS), perceived preferences during cooking as well as identify whether users are aware of the health challenges due to poor cooking and describe community opinions of ICS for rural communities in Uganda. The interviews were conducted on household levels across all the regions covering Uganda's major rural regions. It was observed that the largest population of rural Ugandans still use the 3 stone stove fire for cooking with a percentage of $53.5 \%$, Charcoal stove, $27.3 \%$, Improved cooking stove, $16.9 \%$, Electric cookers, $1.2 \%$, LPG $0.7 \%$ and biogas $0.5 \%$ for the preparation of their various types of cooked foods while forest firewood is the commonly used biomass fuel for cooking with a percentage of $66.8 \%$ compared to Charcoal, Briquettes, Saw dust and others with a percentage of $27.1 \%, 0.7 \%, 0.7 \%, 1.1 \%$ respectively. This reveals the great majority of users whose life is at risk as 3 stone stoves are characterized by low efficiency and high smoke production which increases the health risks of the users as well as increase the risk of deforestation rates. Household cooks showed great willingness to pay for a novel stove type in all the 4 regions but from the survey data, it was indicated that the preferences varied from one region to another with a great majority preferring minimal smoke production with increased heat retention capacity. It was revealed that $91.4 \%$ of the interviewed house-
\end{abstract}


holds were aware of the health challenges due to poor cooking methods which they resolved by using open space during cooking. There was variation in the quantity of food cooked in a day, time spent on cooking and how often the cooking is done from one region to another due to the difference in economic activities as well as the different climate factors. While using cooking stoves, users preferred large cooking pot space with minimal smoke production and rapid heating. Such information can act as a basis for the design of an improved cooking stove for the rural Ugandan community as engineered products must be designed to suit the needs of the end-user.

\section{Keywords}

Cooking, Fuel, Improved Cooking Stoves, Health

\section{Background}

About 3.1 billion people living in low and middle-income countries worldwide rely on polluting fossil fuels and technologies for cooking [1] with 1.4 billion deprived of grid electricity [2] and $85 \%$ of those people living in rural areas [3]. The cooking in these countries is being conducted basically using 3 stone fire or open fire in poorly ventilated structures [4]. These have been associated with extremely low efficiency with $93 \%$ of the energy generated being lost during cooking [1]. This has not only resulted in indoor air pollution [5] but also contributed to regional deforestation and forest degradation due to increased dependence on the wood, crop residues and untreated coal [6]. It's reported by WHO that about 4.3 million premature deaths were due to exposure to household air pollution in 2012 alone [7]. It has been indicated that women and children disproportionately experience higher household air pollution exposure since they play important roles in doing indoor work and cooking [8] as shown in Figure 1. In the need to address these issues globally, improved cook stove distribution

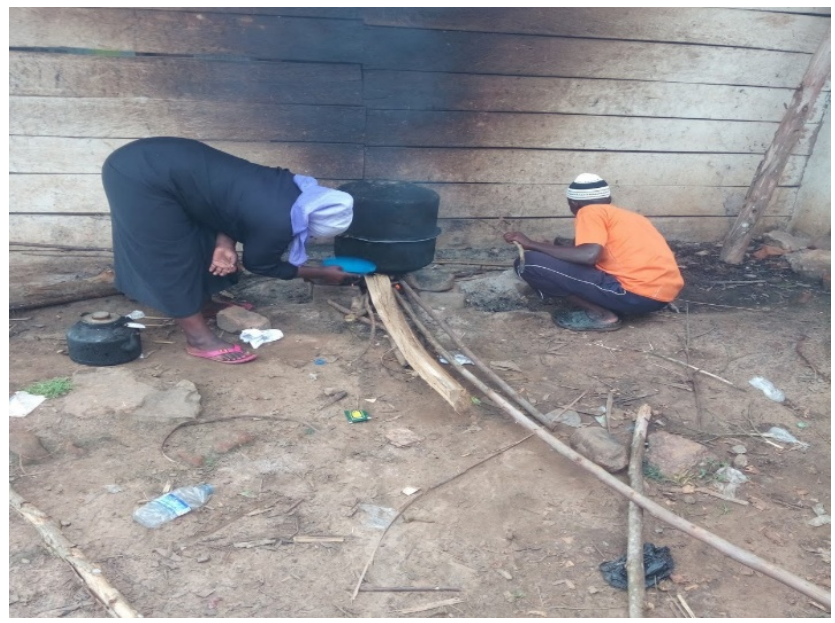

Figure 1. Food preparation by women and children using an open 3-stone stove fire across rural Uganda. 
programs and studies to replace traditional cooking methods with cleaner more efficient ones are continuing to grow in scope and magnitude [9], such as gas, electric and biomass-fuelled technologies have been designed and disseminated [10]. These improved cook stoves have registered some success such as rocket-type stoves which have reduced fuel use by $33 \%$ and forced air stoves which have reduced fuel use by $40 \%$ as compared with 3 -stone fires [11]. With the addition of a fan to the rocket type stoves, the fuel use reduced by $42 \%$, CO emission by $91 \%$ and PM by $94 \%$ compared to the three stone fire. When biochar is produced alongside cooking, this can offer several other benefits to the weathered soils. The use of biochar for soil amendment has been identified as one of the current solutions to increase agricultural yields and boost crop production. Stoves that offer clean cooking with the possibility to produce biochar can be seen to be very competitive. Before any technology is developed or improved, it is important to investigate the needs of the end user so that any advancement made is geared towards addressing the needs of the end user. This provided a basis for this study through studying the different community cooking practices and challenges, proposed possible options from an informed point of view and came up with technology that answers the demands and needs of the society.

\section{Situational Analysis of Uganda}

Uganda is a landlocked country located in the Eastern part of Africa. It's boarded by Kenya in the East, Democratic Republic of Congo in the west, South Sudan in the North, Rwanda and Tanzania in the south with a population of 45.74 million people [12] equivalent to $0.59 \%$ of the world's total population. For easy administration, Uganda has been further divided into 4 regions including the Northern, Central, Eastern and Western regions as shown in Figure 2.

The United Nations High Commissioner for Refugees (UNHCR) report (2016) [12] indicates that access to energy is a real challenge and several attempts have

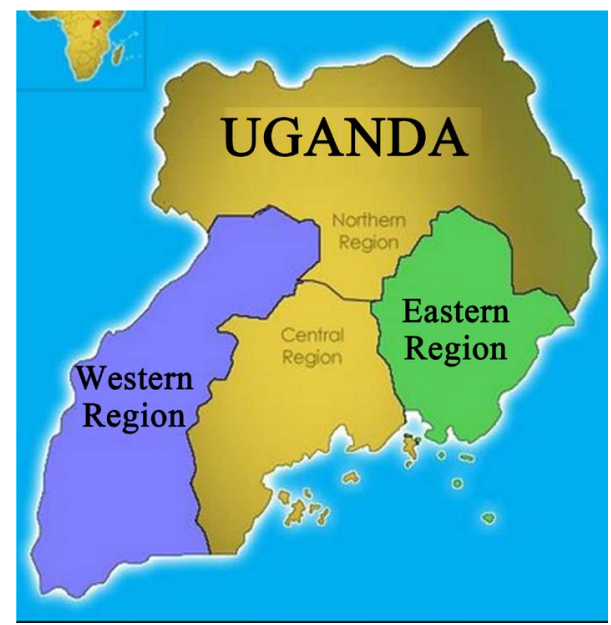

Figure 2. A map of Uganda showing its regions as study areas for this study.

(https://www.researchgate.net/figure/Map-of-Uganda-showing-the-regions-of-the-countr y fig1 334398273). 
been designed to curb down the challenge with the first global strategy being Safe Access to Fuel and Energy. This situation has been worsened by use of inefficient open fires and 3 stone stoves by the rural households. In addition, cooking is done in poorly ventilated kitchen which cause indoor air pollution and predisposing cooks to health conditions such as respiratory infections [12], Exposure to biomass burning particles is strongly associated with cardiovascular disease, respiratory illness, lung cancer, asthma and low birth weights [13]. The UNHCR Uganda SAFE strategy works hand in hand with the Office of the prime minister in Uganda, to have the 4 objectives fulfilled within the off grid areas including 1) Improved household access to fuel-efficient technologies and renewable energy, 2) Improved access to fuel-efficient technologies and renewable energy at institutions within and around settlements 3) Community based management of woodlots and multipurpose plantations for fuel, livelihoods improvement and environmental protection, 4) The integration of energy requirements into emergency preparedness and response plan. The Global Alliance for clean cook stoves, reports that 35 million people are affected by exposure to cook stoves' smoke with 13,000 people experiencing premature death every year within Uganda [14]. This basically affected women and children who spent their time in Kitchen preparing food. According to the Uganda National Environment Management Authority report [13], it is reported that burning biomass contributes to emission of greenhouse gases in form of black carbon, $\mathrm{CO}_{2}$ that cause climate change. To curb down the issues of emission of black carbon, and environmental degradation by the citizens during farming, charcoal making, accommodation, industrialization among others, using deforestation to raise firewood for cooking, several environmental management activities have been undertaken over years which include construction and use of energy saving stoves such as portable and fixed rocket Lorena stoves, Uga stove and the Save 80 stove at both household and institutional levels; individual and community tree planting, community environmental awareness campaigns, use of solar energy, use of briquettes, formulation of community environment action plans for refugee settlement, capacity building, tree marking and conservation of agriculture [12]. Notwithstanding, research further reveals that three billion people worldwide still rely on some form of solid fuel i.e. traditional biomass and coal to meet their cooking and heating needs [15] [16]. This becomes a big threat to the forest resources and the air pollution at large in the developing countries mainly for Uganda whose birth rate is high with it being ranked the second in the whole world since the main source of biomass fuel is obtained by deforestation. Biomass stoves have all along been improved and modified in designs to make them more effective in their operations and functioning alongside other types of stoves especially to mitigate the short and long term effects of biomass usage for fuel. The general goals for the most improved cooking stoves are called "triple benefits" i.e. time saving and improved health, preservation of forests and associated ecosystem services and reducing emissions that contribute to global cli- 
mate change [17]. Traditional biomass stoves used are simple structures made from clay or having stone or metal tripods and have been discovered to be very inefficient because they have poor air flow and insulation. As a result, they consume a lot of biomass and produce high levels of indoor air pollution. Their thermal efficiency is stated to be as low as $10 \%$ to $15 \%$. Thus $85 \%$ to $90 \%$ of the energy content being lost as heat to the environment [18]. The crucial contribution of future research in alleviating the burden of disease associated with the use of solid fuel, however, lies less in evidence-based advocacy, thus a great deal of evidence based research effort is needed to mitigate these global challenges and has prompted this research.

\section{Methodology (For All Study Areas)}

\subsection{Survey on Cooking Practices and Data Analysis}

A total sample of 759 households were randomly selected from 13 districts across the different regions of Uganda including the northern $19.8 \%$, eastern $12.9 \%$, central $29.0 \%$ and western region $38.3 \%$ revealing the required research data on cooking methods, preferences, commonly used biomass fuels, quantity of fuel/biomass used per day, source of cooking fuel, willingness to pay for the novel stove type, desired design features on the cooking stoves such as port diameter and size, knowledge of health effects arising from indoor pollution, prevailing cooking practices, quantity of food cooked in a day, time spent on cooking a day, frequency of cooking, commonly cooked foods by region, awareness to products of incomplete combustion such as biochar, as well as views on the benefits of ash generated. The views and findings arising from this study form a strong basis on the design of an improved cooking stove that can address the needs of the end user. Data was analyzed statistically using SPSS (IBM 21) Software.

\subsection{Distribution of Respondents by Districts}

The data was gathered by visiting each household with an individual research assistant who would identify the personnel engaged in the cooking activities to respond to the research questions as per set objectives such as food cooked most often, amount cooked, cooking duration, approximate amount of fuel wood consumed, dimensions of the pot used mostly for cooking this food among others.

\subsubsection{Responses on Fuel Used}

During the process of cooking, fuel is the most important requirement as it's the primary source of heat. In this survey, the primary cooks were interviewed to find out the most preferred cooking method, the commonly used biomass fuel, its quantity per day as well as its source. In order to establish more facts on firewood collection which is considered as the main biomass used, questions to gather more information related to the firewood were asked. Alongside cooking, more details on the byproducts of firewood during cooking such as charcoal and 
ash plus their various uses were asked such as ironing and lighting stoves (for charcoal) and it being crashed and taken into the garden. It was important to establish the different fuel types in the respective districts to establish if the results are similar of different. This is because various fuels have different densities and pack differently within the cooking stoves. It would offer guidance on whether the stove technology built in the Eastern region would work in the Western region and vice versa.

\subsubsection{Responses on Commonly Cooked Food}

It should be noted that the quantity of fuel used and the time of cooking depends on the type of food being cooked. Hard cereal foods require more time to cook and subsequently consume more fuel while fresh foods are easy to cook requiring less fuel and time. The interviewer went further to find out the most commonly cooked foods by regions and their multiple responses were obtained and recorded. This was aimed at investigating if similarities would exist so that there can be any relationship or variation in stove technology development. In order to gather more information, the respondents were asked to find out the number of people being cooked for, because this has a great impact on the quantity of fuel used as well as the nature of the pot size being used. The questions were further asked to find out the quantity of food being cooked, time spent on cooking a day and how often the cooking is done. This was done to determine the specific fuel consumption rate as, the ratio of the quantity of fuel wood consumed during the day per pot size.

\subsubsection{Responses on Stove Dimensions and Preferences}

In this section, the interviewers went into more details to gather information on the measurements of the stoves being used i.e. diameter and height; and what their preferences would be in case of any innovations in the stove being used. The respondents were requested to present their cooking stoves from which the diameters and heights were measured and recorded.

The household primary cooks were further interviewed to find out what other changes they would prefer to be made on the new stoves that would be developed to improve on their adoptability

\subsubsection{Responses on Indoor Air Pollution Awareness}

In order to find out the dangers faced with poor cooking such as indoor air pollution and its associated problems such as respiratory diseases, the interviewers requested the primary cooks to identify their awareness on the health challenges that come with indoor pollution. And what they are trying to do to avoid the dangers associated with indoor pollution that come with cooking using stoves. This would form a basis for sensitization in the course of this discipline to save human health and to develop a technology that would have less effects.

\subsubsection{Responses on Willingness to Pay for a Novel Stove}

One of the major challenges that have been reported towards the adoptability of 
improved cooking stoves in Uganda and the entire world at large has been the high prices which makes the stoves to be affordable to only rich -families, leaving the poor and the overly affected community not helped So the cooks were interviewed to determine their willingness to pay for the novel stove type in case its developed and supplied to them or if subsidies can be advocated for incase their interest doesn't match their ability to afford

\section{Results and Discussion}

It was observed that the largest population of rural Ugandans still use the 3 stone stove fire for cooking with a percentage of $53.5 \%$, Charcoal stove, $27.3 \%$, Improved cooking stove, $16.9 \%$, Electric cookers, $1.2 \%$, LPG $0.7 \%$ and biogas $0.5 \%$ for the preparation of their various types of cooked foods while forest firewood is the commonly used biomass fuel for cooking with a percentage of $66.8 \%$ compared to Charcoal, Briquettes, Saw dust and Others with a percentage of $27.1 \%$, $0.7 \%, 0.7 \%, 1.1 \%$ respectively

Use of the 3 stove stone fire is characterized by low efficiency and high smoke production which increases the health risks of the users as well as the deforestation rates. From the survey results, it was revealed that the mothers were the key players involved in cooking and as such, they are more vulnerable to challenges of indoor pollution. Amongst the regions (Figure 3), the western region showed a high response rate with Ssembabule (Figure 4) showing the highest percentage of response amongst the districts

From the survey data collected, it was observed that firewood is the most commonly used biomass fuel while using the three stone stove fire with the Northern region exhibiting the greatest percentage of $60.6 \%$ with the quantity of (4 - 6) kg used per day. The central region registered a low quantity per day of (2 - 4) $\mathrm{kg}$ used per day. This can be associated with the highest presence of charcoal stoves (44.5\%) which can supplement the three stone stove fire. It was also

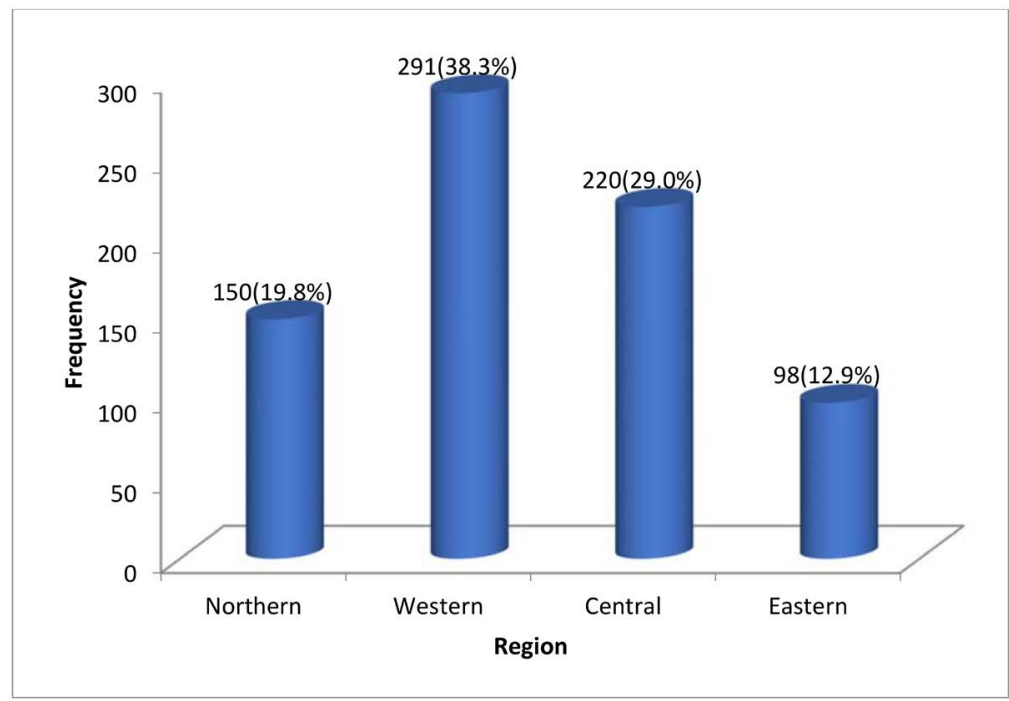

Figure 3. Distribution of respondents by region. 


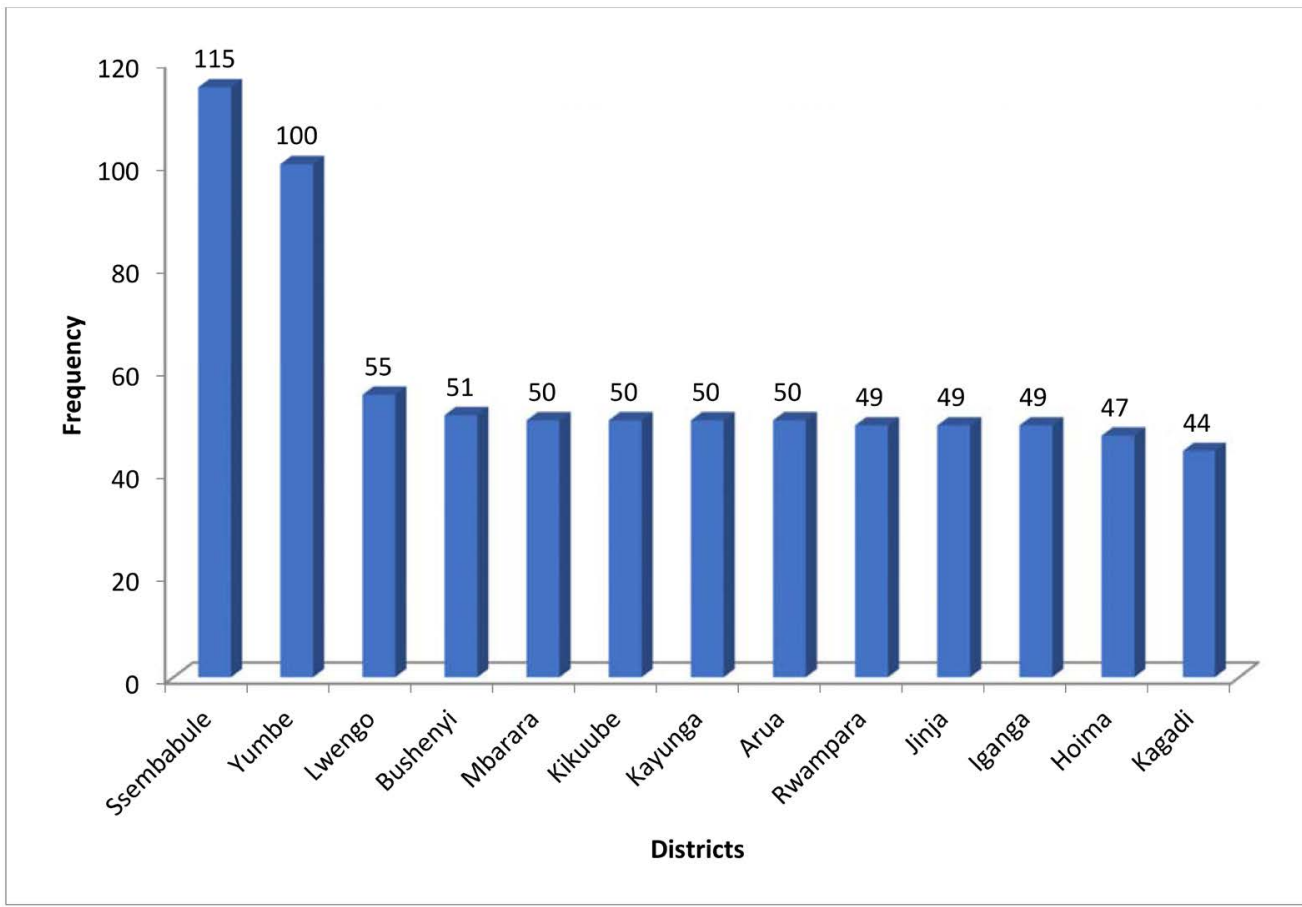

Figure 4. Distribution of respondents by districts.

observed from the data collected that the quantity of firewood used per day depended not only on the quantity of food cooked in a day which on average is (4 6) but also on daily cooking frequency. In furtherance, most of the household in all regions cooked at least twice per day, represented by (51.9\%) of the population and the time spent while cooking in a day ranged between $(2-4$ hours. It was also identified that the quantity of food prepared depended on the number of people being usually cooked for at home and where this number varied from one region to another i.e. (3 - 5) people in Central region, and (5 - 8) people in the other three regions. In all these regions, it's observed that the major source of all firewood is the forest. The northern and western region showing the greatest percentages i.e. $73.3 \%$ and $73.1 \%$ respectively. The survey indicated that children (for western and central regions) and mothers (for Northern and Eastern regions) were responsible for the gathering of firewood at home spending less than 2 hours for Central and Eastern regions whereas (2 - 3) hours for Western and (3 - 4) hours for Northern Region. In general, a considerable amount of time is wasted gathering firewood which would otherwise have been used to promote other economic activities such as fishing, farming among others. This affects Uganda's economic growth as productive efforts are not fully utilized. It was observed that the greatest percentage (64.2\%) of the households do not produce any charcoal during cooking. This reveals that they exercise combustion process during cooking and are directly exposed to the effects of this direct exposure such as carbondioxide, carbon monoxide, particulate matter, soot, volatile organic carbon, Sox, $\mathrm{NO}_{\mathrm{x}}$, among others. This needs urgent mitigation to save their lives. Of those that produce it $(32.8 \%),(66.7 \%)$ for cooking, while the rest 
use it for ironing (21.4\%). This further reaffirms that the great majority of Ugandans are not aware the production benefits of efficient use of biomass for biochar production alongside cooking. It is a route that is worth investigating to compliment these benefits. Of those exercising combustion during cooking and generate ash during the process, $56.7 \%$ of them are not aware of its benefits and just expose this as a normal waste. This implies that this waste contributes to the waste stream if not well managed. The remaining percentage of $32.6 \%$ takes it to the garden and is used as a manure. It should be noted that ash is a mineral matter content with constituents such as potassium, magnesium, calcium and several other mineral matter which are vital as plant nutrients. These minerals need proper harnessing and channeling to serve the relevant plant values. In this survey, the commonly cooked foods vary from region to region as shown in Figure 5. This is due to the various ethnic tribes distributed across the regions of Uganda with each tribe having its own food. Despite this variation, Banana food seemed to be a common food type for all the regions consumed by $65.4 \%$ in the Western part, (65.4\%) in the Northern and (50.7\%) in the Central part. This reveals that a stove developed for cooking could easily be adopted in all these regions given the similarity in food consumption. Cook ... Subsequently the most common cooking practice was boiling.

It was further observed that the diameters and heights of various cooking stoves measured in the field revealed significant variation in proportions for both diameter and height ranging between $35 \pm 15.3 \mathrm{~cm}$ and $43.7 \pm 29.3 \mathrm{~cm}$ was respectively. This justifies that within the field, there is no standard supplier of these cooking stoves and users procure these products from different suppliers. These sizes have affected the chemistry of cooking accordingly. The wider the pot size, the more stable is the cooking and the cooking speed depends on the amount of incoming air determining the combustion temperature and speed consequently. From the survey data, it was further discovered that all the interviewed households expressed a greater will of paying for a novel stove type with the Northern region showing the greatest will (100\%) compared to other regions

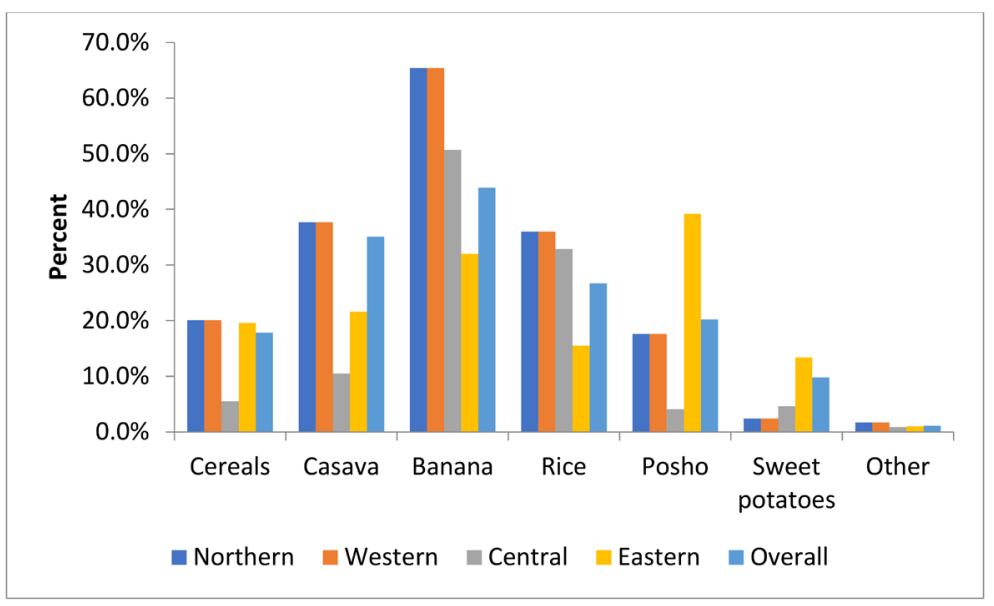

Figure 5. Commonly cooked foods by region. 


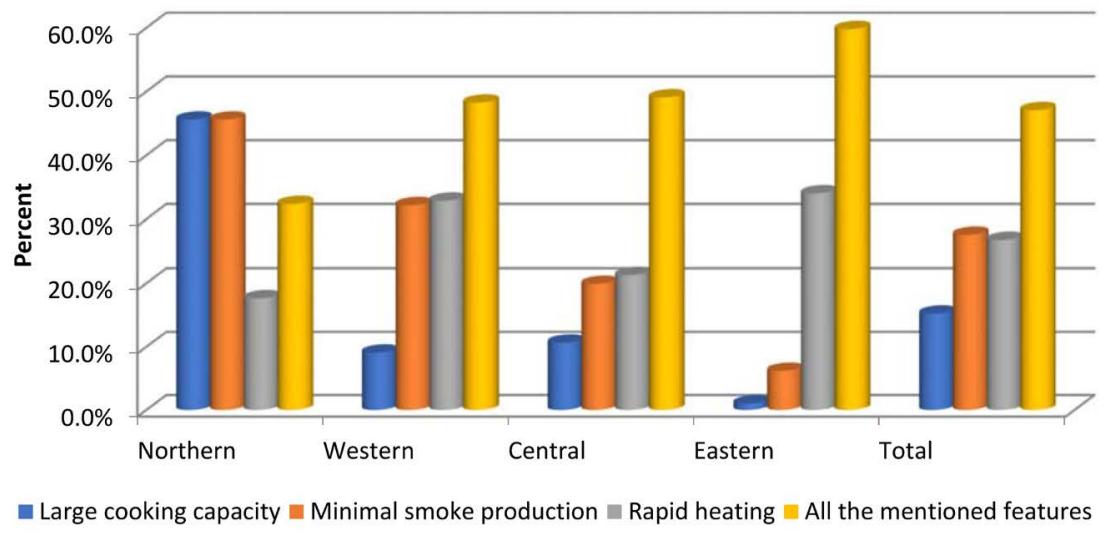

Figure 6. Features households would find desirable in cooking.

with an average of $89.4 \%$ from all the 4 regions of Uganda. This maximum willingness and expression reveal the poor cooking practice, that users are not happy to carry on, as well as integrating several other benefits that come with cooking. Users would thus leverage on increased heat retention, minimum smoke production as well as maximum energy efficiency during cooking. The desired user preferences are summarized in Figure 6. In general, these user preferences reveal the need to develop an improved cooking stove with potential to address their desires.

Field results further revealed that $91.4 \%$ of the respondents used the stoves only for cooking and had not seen any extra benefit that comes along with this. It would be novel to exploit the heat energy generated during cooking, as well as making maximum use of the generated products from biomass heating as part of the cooking process to increase user benefits.

\section{Conclusion}

Following a successful survey, it was indicated that the respondents expressed a high demand for Improved Cook Stoves (ICS) that could serve their needs and meet their preferences. Because of Uganda's dependency on agriculture, households were interviewed to identify the extent of biomass usage as a fuel, and their extent of knowledge regarding the products of biomass combustion. Increasing their awareness about these products could add value on improving soil properties and boost the agricultural sector overwhelmingly. Based on the data from this survey, most of the households are willing to adjust from the use of 3 stone fire to ICS that can help in meeting the needs of the end user such as, good heat retention, minimal smoke production, ease of use as well as its ability to generate other co-products alongside heat. In this case, it is important to investigate the ability of electricity generation from waste heat during cooking for small scale electrical appliances such as phone batteries, torches, radios etc., to increase value addition during cooking. Such ICS can be operated at optimal operating conditions to generate co-products such as biochar. Such would be a novel stove 
type to serve the end user's need based on the current user vacuum. The development of such a multipurpose stove and its adoptability can have a great value on saving lives, reducing on deforestation thus mitigating climate change as well as offering several other value additions in serving the needs of the end user. The results from the survey can act as a basis to inform the design of an improved cooking stove that can serve the needs of the end user based on the presently identified gaps. Such a stove should be economically affordable to the users, so that a wider population can benefit from it.

\section{Acknowledgements}

This work was financially supported by a research grant from the Government of Uganda under Makerere University Research and Innovation Fund (Mak-RIF) grant number MAK/RIF/481/19. The authors are very grateful for this funding and support for this research.

\section{Conflicts of Interest}

The authors declare no conflicts of interest regarding the publication of this paper.

\section{References}

[1] Chen, B.R. (2013) Design and Development of a Low-Cost, Electricity-Generating Cooking. Journal of Power and Energy, 227, 803-813. https://doi.org/10.1177/0957650913498733

[2] Ehsana, M.S. (2015) Performance of an Electricity-Generating Cooking Stove with Pressurized Kerosene Burner. Procedia Engineering, 105, 619-627. https://doi.org/10.1016/j.proeng.2015.05.040

[3] O’Shaughnessy, S.D. (2012) Small Scale Electricity Generation from a Portable Biomass Cookstove: Prototype Design and Preliminary Results. Applied Energy, 102, 374-385.

[4] Adkins, E. (2010) Field Testing and Survey Evaluation of Household Biomass Cookstove in Rural Sub-Saharan Africa. Energy for Sustainable Development, 14, 172-185. https://doi.org/10.1016/j.esd.2010.07.003

[5] Ritchie, H. (2019) Indoor Air Pollution. https://ourworldindata.org

[6] Bukola, O. (2012) Effects of Unsustainable Use of Biomass Energy for Cooking and Strategies for Their Reduction in Developing Countries. Developing Country Studies, 2, 19-25.

[7] WHO (2016) Global Estimates of Burden of Disease Caused by the Environment and Occupational Risks. World Health Organization, Geneva. http://www.who.int/quantifying ehimpacts/global/en

[8] Clougherty, J. (2010) A Growing Role for Gender Analysis in Air Pollution Epidemiology. Environmental Health Perspectives, 118, 167-176.

https://doi.org/10.1289/ehp.0900994

[9] Piedrahita, R., Dickinson, K., Kanyomse, E., Coffey, E., Alirigia, R., Hagar, Y., et al. (2016) Assessment of Cookstoves Stacking in Northern Ghana Using Surveys and Stove Use Monitors. Energy for Sustainable Development, 34, 67-76. 
https://doi.org/10.1016/j.esd.2016.07.007

[10] Shan, M., Carter, E., Baumgartner, J., Deng, M., Clark, S. and Schauer, J. (2017) A User-Centered, Iterative Engineering Approach for Advanced Biomass Cookstove Design and Development. IOP Publishing Ltd., Bristol.

https://doi.org/10.1088/1748-9326/aa804f

[11] O'Shaughnessy, S.J. (2014) Field Trial Testing of an Electricity-Producing Portable Biomass Cooking Stove in Rural Malawi. Energy for Sustainable Development, 20, 1-10. https://doi.org/10.1016/j.esd.2014.01.009

[12] UNHCR (2016) Uganda Energy and Environment Program Strategy. UNHCR Uganda Energy and Environment Programme Strategy, 2016-2020.

[13] (2013) Uganda National Environment Management Authority Report. http://nema.go.ug/content/strategy-and-planning-nema's-annual-corporate-reportfy 201314

[14] (2014) Global Alliance for Clean Cook Stoves. Reports. https://www.cleancookingalliance.org/binary-data/RESOURCE/file/000/000/414-1. pdf

[15] Legros, G.H.A. (2009) The Energy Access Situation in Developing Countries: A Review Focusing on the Least Developed Countries and Sub-Saharan Africa. UNDP \& WHO.

[16] Lertsatitthanakorn, C.J. (2014) Study of Combined Rice Husk Gasifier Thermometric Generator. Energy Procedia, 52, 159-166.

https://doi.org/10.1016/j.egypro.2014.07.066

[17] Jouland, M.A.P. (2012) Benefits and Costs of Improved Cook Stoves: Assessing the Implications of Variability in Health, Forest and Climate Impacts. PLoS ONE, 7, e30338. https://doi.org/10.1371/journal.pone.0030338

[18] Bethge, J.A. (2013) What Users Can Save with Energy Efficient Cooking Stoves and Ovens.

https://energypedia.info/wiki/What Users Can Save with Energy-efficient Cooki $\underline{\mathrm{ng} \text { Stoves and Ovens }}$ 